\title{
Determinantes DEL ENDEUdAMIENTO DE LOS HOGARES EN MÉXICO: UN ANÁLISIS CON REDES NEURONALES
}

\author{
Héctor Eduardo Díaz Rodríguez, ${ }^{a}$ Miriam Sosa Castro ${ }^{b}$ \\ y Alejandra Cabello Rosales ${ }^{a}$
}

Fecha de recepción: 15 de octubre de 2018. Fecha de aceptación: 6 de mayo de 2019.

http://dx.doi.org/10.22201/iiec.20078951e.2019.199.67463

\begin{abstract}
Resumen. En ańos recientes el crédito al consumo en México creció de manera importante. Las tarjetas de crédito, que representan $52 \%$ de los créditos en el país, crecieron $19 \%$ de 2011 a 2018; mientras que el endeudamiento promedio por tarjeta creció $62 \%$. Dicho crecimiento genera problemas de sobreendeudamiento de los hogares mexicanos. Empleando microdatos de la Encuesta Nacional de Ingresos y Gastos en los Hogares (ENIGH), la presente investigación busca encontrar los factores del sobreendeudamiento en los hogares, y aportar una explicación del mismo para ello, se utilizó la metodología de redes neuronales. El principal determinante de sobreendeudamiento de los hogares mexicanos es la existencia de un crédito bancario, hecho que indica una transferencia de largo plazo del ingreso familiar hacia este sector financiero.
\end{abstract}

Palabras clave: endeudamiento financiero; crédito al consumo; poder adquisitivo; banca comercial; redes neuronales artificiales.

Clasificación JEL: D14; E51; G21; C45.

\section{Determinants of DebT in MeXican HOUSEHOLDS: A NEURAL NETWORK ANALYSIS}

\begin{abstract}
In recent years, consumer credit in Mexico has grown in significant ways. Credit cards, which represent $52 \%$ of credit in the country, grew by $19 \%$ from 2011 to 2018 , while the average debt per card increased by $62 \%$. This increase generates problems of over-indebtedness in Mexican households. Using microdata from the National Income and Expenditure Survey (NIES), this research seeks to identify the factors that affect over-indebtedness in households, and to offer an explanation of said phenomenon using a neural network methodology. The principal determinant of overindebtedness in Mexican households is the existence of bank credit, given that this indicates a long-term transfer of family income to the financial sector.
\end{abstract}

Key Words: financial debt; consumer credit; acquiring power; commercial banking; artificial neural networks.

${ }^{a}$ Universidad Nacional Autónoma de México (UnAm), México; ${ }^{b}$ Universidad Autónoma Metropolitana, Unidad Iztapalapa, México. Correos electrónicos: diazrhe@economia.unam.mx; msosac87@hotmail.com y acr2001mx@yahoo.com.mx, respectivamente. 


\section{INTRODUCCIÓN}

Recientemente, el crédito al consumo en México ha experimentado un crecimiento importante, como consecuencia, entre otras cosas, de la expansión crediticia por parte de tiendas departamentales y de retail, que acaparan a un segmento de la población de mayor riesgo y poco cubierto por los bancos tradicionales comerciales. Dicha expansión crediticia se ha favorecido por la creciente necesidad de utilizar crédito por parte de un segmento de la población que tiende a ser mayor, y a medida en que los salarios reales experimentan pérdidas recurrentes de poder adquisitivo.

El crédito al consumo permite a diferentes estratos de la población acceder a bienes de consumo duradero a cuenta de su ingreso futuro (como son automóviles o viviendas), suavizando así su patrón de consumo a lo largo del ciclo vital (Salgado y Chovar, 2010; Martínez-Carrascal y Río, 2004). Lo anterior resulta aún más relevante para el caso de las familias de estratos socioeconómicos bajos, en donde el ingreso, el acervo de capital y la generación de ahorro son, por lo general, bajos, lo que dificulta la adquisición de este tipo de bienes. Así, el crédito constituye una importante herramienta para la adquisición de bienes de consumo duradero. Sin embargo, la contraparte de un crédito es el pago de intereses, lo que implica que "un aumento de las deudas representa una mayor carga financiera en forma de pagos de intereses y amortización y puede reducir, en ciertas circunstancias, la capacidad de respuesta del sector ante una evolución desfavorable en su ingreso" (Martínez-Carrascal y Río, 2004, p. 49).

El endeudamiento representa una oportunidad de incrementar el consumo y la inversión; no obstante, los inconvenientes surgen cuando se hace uso desproporcionado de este factor, exponiendo al usuario a caer en situación de impago, poniendo en riesgo el patrimonio familiar, y de forma agregada, comprometiendo la estabilidad económica. En este sentido, el endeudamiento financiero impone una mayor carga y reduce la capacidad de respuesta de la economía frente a variaciones en las tasas de interés, intensificando los efectos de un desequilibrio económico.

Debido a los efectos adversos que genera el sobreendeudamiento, tanto a nivel macroeconómico como dentro de los hogares, su estudio es cada vez más relevante. Este trabajo tiene como objetivo analizar cuáles son los determinantes del sobreendeudamiento de los hogares en México (que representan gastos superiores a $40 \%$ de sus ingresos), así como ofrecer algunas posibles explicaciones en términos de los factores político-económicos que favorecen esa configuración. 
En principio, el análisis propuesto es de corto plazo y utiliza datos de la Comisión Nacional Bancaria y de Valores (CNBV, 2018) para analizar, por el lado de la oferta, el incremento en el crédito y las probabilidades de impago. Y, por el lado de la demanda, se utiliza la ENIGH, que permite analizar los usos del crédito, el nivel y los factores que determinan el sobreendeudamiento de los hogares. La metodología que se ha elegido para analizar el tema es la de redes neuronales artificiales (RNA), que permite analizar tanto relaciones lineales como no lineales.

El trabajo se organizó de la siguiente manera: la segunda sección revisa estudios relacionados con el tema propuesto. La tercera sección presenta, con datos de la ENIGH (INEGI, 2016), ${ }^{1}$ un análisis estadístico de la situación de endeudamiento de los hogares en México; mientras que en la cuarta sección, se describe la metodología de RNA. Los resultados del análisis se localizan en la quinta sección y, por último, se presentan las conclusiones derivadas del estudio.

\section{REVISIÓN DE LA LITERATURA}

El papel de crédito y del endeudamiento en una economía, se ha estudiado ampliamente desde diversas perspectivas. Por ejemplo, desde el lado del crédito, por lo general se analiza el papel del crédito para la inversión y, en ese sentido, el sistema financiero como una manera eficiente de vincular unidades superavitarias con demandantes de crédito para inversión ${ }^{2}$ (Samuelson y Nordhaus, 1992).

En términos de los usos del crédito, es mucho más abundante la literatura desarrollada para analizar el crédito a la inversión, que la vinculada con el crédito al consumo. Schumpeter (1976) reconoce que "No forma parte de la naturaleza de ningún individuo, contraer deuda para el consumo [...]. En consecuencia, no nos interesa el fenómeno del crédito para el consumo". La economía y, en particular, el sistema financiero analizado por Schumpeter dista mucho del actual.

Desde el punto de vista del endeudamiento, la teoría de Minsky (1992, 2008) ha sido par excellence, el punto de partida del análisis de distintos

1 Cabe aclarar que lo que se considera como endeudamiento es lo que se registra en la ENIGH, es decir, sobre todo endeudamiento en mercados formales como bancos comerciales, microfinancieras y otras.

2 Ese punto de vista de libro de texto de economía, pareciera estar en desuso a partir de los planteamientos de endogeneidad y no neutralidad de dinero hechos por la escuela poskeynesiana. 
esquemas de endeudamiento en empresas, con la teoría de la inestabilidad financiera, que sostiene que los préstamos atraviesan tres etapas diferentes (cobertura, especulativa y Ponzi). El propio Minsky reconoce que su análisis de financiamiento y endeudamiento está pensado sobre todo para empresas, aunque no descarta la posibilidad de que, en algún momento, esquemas similares de reproducción de endeudamiento pudieran ocurrir en los hogares (Minsky, 2008).

De manera reciente -a la par de que los sistemas financieros adquieren mayor relevancia-, tanto en la esfera nacional como en el ámbito global, se ha dado un crecimiento importante de los estudios que analizan el papel que tiene la inclusión financiera (es decir, el grado de vinculación de la población con el sistema bancario) para explicar el crecimiento económico; en ese sentido, la mayoría de las investigaciones relacionadas, contemplan un amplio número de variables que, con diferencias de grado, otorgan a la inclusión financiera un papel fundamental en el desarrollo económico de las naciones o regiones, mediante tres principales mecanismos:

1) El sistema financiero mejora la eficiencia en la asignación de recursos posibilitando que se incremente la inversión (Rajan y Zingales, 1995; Claessens, 2005; Demirg y Levine, 2008; Clarke et al., 2003; Honohan, 2004; Dehejia y Lleras, 2007; Levine, 2005).

2) Suavizando los ciclos económicos y mejorando el entorno macroeconómico (Dabla-Norris y Srivisal, 2013; Kose et al., 2003).

3) A nivel micro, el incremento en el acceso al crédito en condiciones más favorables que en los mercados de crédito informal (Campero y Kaisser, 2013; Karlan et al., 2013; Straub, 2003), y con ello, acceder a la posibilidad de incrementar el capital, tanto en términos de activos físicos como de capital humano (educación y salud).

A diferencia de lo propuesto por el Banco Mundial (2013), en el Global Financial Development Report, una mayor inclusión financiera pareciera no estar necesariamente vinculada de manera directa con un mayor nivel de bienestar de la población; en efecto, como se analiza más adelante, parecieran ser otros los mecanismos a través de los cuales, la mayor penetración del sistema financiero y del crédito han impactado a los hogares en México.

Ello se puede observar a través de creciente proporción del crédito en el país que se destina al consumo más que al financiamiento de proyectos productivos, lo que da como resultado, que una pequeña proporción de los re- 
cursos disponibles en el sistema bancario se destinen a la acumulación y al incremento del acervo de capital.

Diversos estudios analizan cómo actúa el crédito en el endeudamiento familiar. En esa dirección, Salgado y Chovar (2010) analiza el impacto de las tarjetas de crédito y la deuda hipotecaria en el sobreendeudamiento de los hogares en Chile. Utilizando un modelo probit y un probit bivariado encuentran que la tenencia de instrumentos de crédito al consumo (como tarjetas departamentales) son los principales factores que determinan el sobreendeudamiento.

Del Río (2002) analiza la situación patrimonial de los hogares españoles; realiza un modelo de corrección de error para identificar los factores asociados al comportamiento de la deuda y encuentra que "la revalorización experimentada por la riqueza inmobiliaria de las familias españolas ha desempeñado un papel relevante en la evolución reciente de sus pasivos" (Del Río, 2002, p. 2).

Martínez-Carrascal y Río (2004, p. 49) reconocen que, si bien hay algunos beneficios asociados a la existencia de crédito bancario, un aumento de las deudas bancarias implica una "mayor carga financiera en forma de pagos de intereses y amortización, y puede reducir, en ciertas circunstancias, la capacidad de respuesta del sector ante una evolución desfavorable en su renta, su patrimonio o el coste de financiación".

Mediante un seguimiento de la expansion del crédito en los hogares en Chile, Ruiz-Tagle et al. (2013) encuentran que este fenómeno ha ocurrido principalmente en los quintiles más pobres de la población. Localizan efectos directos de shocks (de salud, ingreso y gasto en educación) sobre el endeudamiento de los hogares; estos efectos son heterogéneos y dependen del nivel de ingreso.

Fatoki (2015) investiga las causas y consecuencias del sobreendeudamiento en Sudáfrica. La evidencia empírica apunta a que existen dos conjuntos de factores los que determinan la existencia de altos niveles de endeudamiento; por un lado, factores desde el punto de vista de la oferta, como créditos muy costosos debido al alto nivel de riesgo, así como de demanda (escasos ingresos y capacidad de pago de la población). Por el otro, factores internos y externos de los países, por ejemplo, el escaso desarrollo del sistema financiero al interior de ellos, o bien, la situación de endeudamiento público, son aspectos que determinan el sobreendeudamiento de los hogares.

Pradilla (2015) analiza las condiciones de endeudamiento de los hogares colombianos con la finalidad de visualizar las características que influyen en las situaciones de sobreendeudamiento. Los hallazgos de la investigación 
revelan la importancia de variables como los ingresos, el saldo de la deuda, el número de integrantes del hogar, la edad y el estado civil del jefe de hogar para la explicación del comportamiento de las condiciones de endeudamiento.

Romero (2018) estudia los factores financieros sociodemográficos que influyen en el sobreendeudamiento en Ecuador. Los resultados sugieren que los principales determinantes son: los ingresos personales, la edad del jefe de familia, el número de miembros del hogar y, nuevamente, la existencia de un vínculo con el sistema financiero, ya sea mediante un crédito hipotecario o bien, con una tarjeta de crédito.

En cuanto a los trabajos que analizan el sobreendeudamiento en México se encuentran los hechos por Morales et al. (2013), quienes estudian la situación de la banca comercial en el país; y observan un deterioro en la cartera vencida de los diferentes segmentos de consumo, lo que se refleja en un sobreendeudamiento por parte de los hogares y familias. Angulo (2014), por su parte, analiza las implicaciones sociales de las prácticas más comunes de las instituciones microfinancieras para aminorar riesgos y enfrentar el sobreendeudamiento de los clientes; la evidencia sugiere que la combinación de componentes económicos y sociales inciden en los programas de microfinanzas, retroalimentando esquemas de endeudamiento cuando la selección original de los destinatarios de crédito no es la adecuada.

A nivel de finanzas personales, existen trabajos en los que se estudian los determinantes del uso de tarjetas de crédito (Vázquez, 2015; Solano et al., 2015) y otros que investigan el uso que se les da a las mismas por parte de distintos segmentos de población (Contreras et al., 2017). Las variables transversales a esos estudios, en donde se produce un uso excesivo del crédito, son coyunturas en donde se realizan gastos médicos, educativos o bien, emergencias familiares. Lo anterior, es un indicador de la insuficiencia de servicios públicos de salud y educación para atender las necesidades de la población sin vulnerar su patromonio.

Sin embargo, no existen estudios que indagen sobre los factores que determinan el sobreendeudamiento en los hogares. Con base en lo anterior, el presente trabajo emplea una metodología robusta y de frontera para analizar los determinantes del sobreendeudamiento en México, utilizando microdatos proporcionados por la ENIGH (INEGI, 2016). Previo al desarrollo matemático, se realizó un análisis estadístico descriptivo a partir de dicha encuesta, permitiendo contextualizar el problema y complementar el análisis empírico. 


\section{CARACTERÍSTICAS DE INGRESO Y GASTO DE LOS HOGARES EN MÉXICO}

El uso creciente de crédito en México puede analizarse también desde la perspectiva de ingresos percibidos por los hogares, en relación con los gastos que realizan. En la versión más reciente de la ENIGH (INEGI, 2016), se puede observar que $46.5 \%$ de los hogares en México tienen gastos totales (gasto corriente + erogaciones de capital) superiores a su ingreso. La condición de posibilidad de que un hogar pueda tener gastos mayores a sus ingresos en un periodo específico es la existencia de ahorro previo, o bien, la posibilidad de acceder a alguna forma de crédito.

En el caso de México, la conformación de la banca comercial y del crédito otorgado por tiendas departamentales y de retail, determina un patrón específico del endeudamiento de los hogares que es necesario entender. En esta dirección, el Consejo Nacional de Inclusión Financiera (2017) refiere que las tarjetas de crédito ${ }^{3}$ son el producto más otorgado por la banca comercial, con 26 millones de contratos registrados a finales de junio de 2016, seguidos de los créditos personales y de nómina, con 10.5 y 5.2 millones, respectivamente. A esas cifras, siguen los créditos grupales con 3.4 millones, los llamados adquisición de bienes de consumo duradero con 2.7 millones y los créditos hipotecarios, con 1.5 millones; los créditos automotrices ocupan el último lugar con 0.6 millones de contratos. Estos datos coinciden, a grandes rasgos, con lo reportado en la ENIGH (INEGI, 2016) (véase gráfca 1).

Lo anterior evidencia que $9.6 \%$ del crédito dirigido a hogares en México se destina al incremento del acervo de capital (adquisición de bienes de consumo duradero, créditos hipotecarios y créditos automotrices); el restante $90.4 \%$ se destina a alguna forma de financiamiento del gasto corriente de los hogares. Así, de forma contraria a lo que la literatura apunta, el crédito en México no está siendo utilizado para adquisición de bienes de capital, o bien inversiones que aumenten las capacidades de los miembros del hogar, sino para adquirir bienes de consumo (alimentos, ropa, calzado, emergencias médicas, etcétera).

La gráfica 2 muestra el número total de tarjetas de crédito y el saldo promedio por tarjeta de crédito; como se puede observar, ambos crecieron de manera importante. El número de tarjetas pasó de 21547000 en junio de 2011 a 25549000 en junio de 2018, con un crecimiento promedio anual

3 Citibanamex es la institución que reportó el mayor número de tarjetas de crédito con 7.4 millones, seguido de ввva Bancomer con 6.1 millones, Bancoppel con 3.4 millones y Santander con 2.8 millones. 
Héctor Eduardo Díaz, Miriam Sosa y Alejandra Cabello

Gráfica 1. El crédito y su distribución en México, 2016

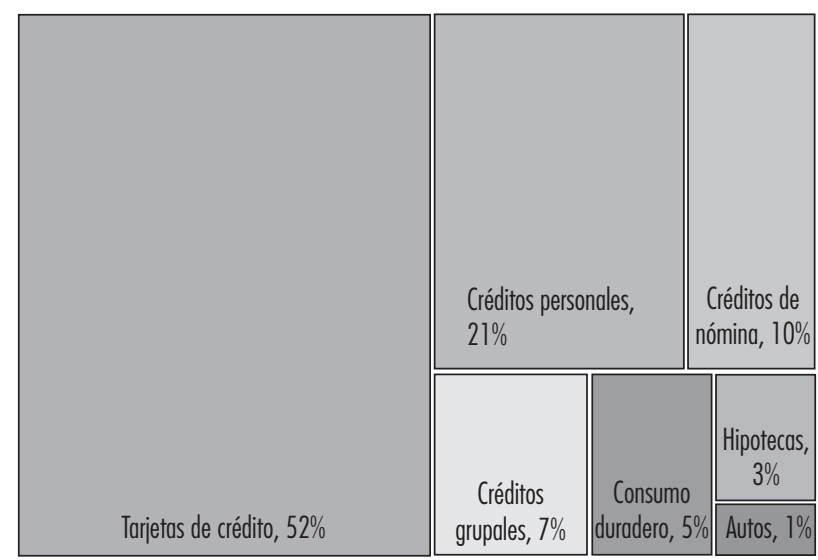

Fuente: elaboración propia con base en el INEGI, 2016.

Gráfica 2. Más personas endeudadas con montos de deuda mayores, 2011-2018

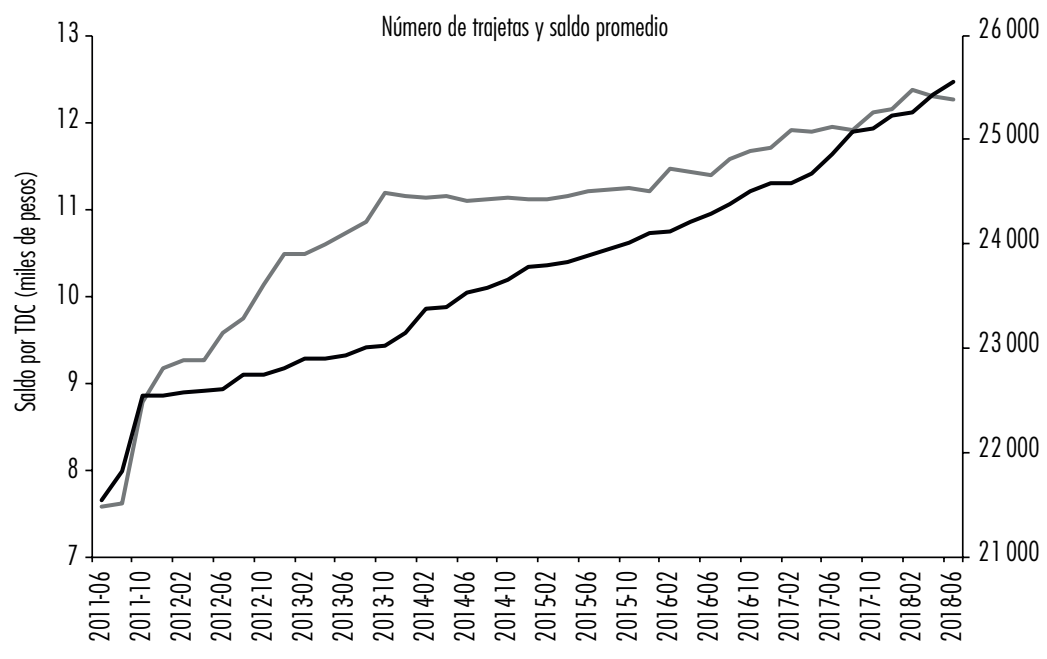

Periodo

— Saldo por TDC (miles de pesos)

— Número de TDC (miles)

Fuente: Comisión Nacional Bancaria y de Valores, 2018. 
de $2.5 \%$. Ello es un indicador, por una parte, del crecimiento del volumen total de crédito al consumo utilizado en la economía, y por otra, de que en el caso de la economía mexicana, el porcentaje de la población que utiliza una tarjeta de crédito como mecanismo de acceso al crédito al consumo, tiende a crecer de manera continua. Por su parte, el monto promedio de las deudas aumentó $62 \%$ en el mismo periodo a razón anual de $9 \%$.

Pero no sólo se ha presentado un crecimiento del endeudamiento familiar, sino que ello, aunado a la falta de crecimiento de los salarios reales, ha dado como resultado que la calidad del crédito empeore de manera significativa. La gráfica 3 muestra la probabilidad de incurrir en impago de tarjeta de crédito para dos segmentos de la población. Como se puede apreciar, el segmento de menor probabilidad de incurrir en impago se reduce, pasando de $93 \%$ en junio de 2011 a $85 \%$ en junio de 2018. En contraparte, el segmento con una probabilidad muy alta de incurrir en impago (mayor a 90\%), crece de manera acelerada, pasando de 0.3 a $2.4 \%$ en el mismo periodo. Ello es un indicador preocupante, si se considera la tendencia; un mayor número de usuarios de tarjeta, con un segmento creciente de probabilidad de impago y un segmento cada vez menor de baja o nula probabilidad de no cubrir con las obligaciones crediticias adquiridas.

Gráfica 3. Calidad del endeudamiento en TDC, 2011-2018

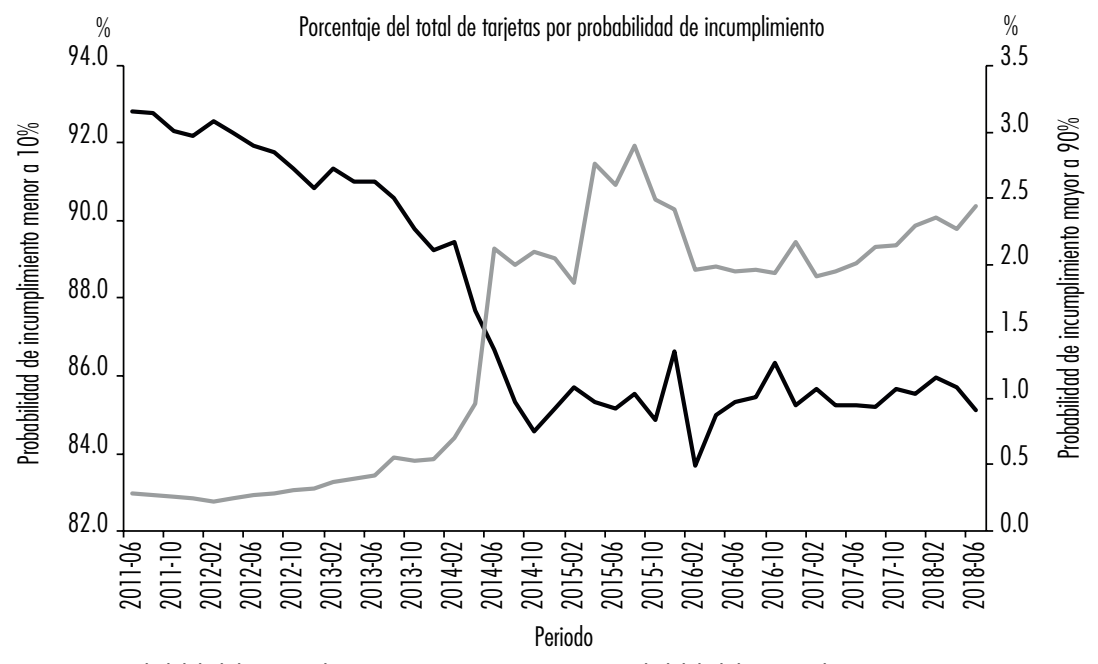

—Probabilidad de incumplimiento menor a 10\% —Probabilidad de incumplimiento mayor a $90 \%$

Fuente: Comisión Nacional Bancaria y de Valores, 2018. 
Para entender dicho comportamiento, es necesario aproximarse a los patrones de ingreso y de gasto de los hogares. La ENIGH (INEGI, 2016) muestra patrones de ingreso, consumo y deudas, que es necesario analizar para entender las características de los hogares y las razones por las cuales deciden endeudarse o no. A continuación, se analizan algunas de esas características a nivel de estadística descriptiva; así se obtiene información preliminar de los patrones de ingreso y de gasto de los hogares, como paso previo al análisis matemático.

La gráfica 4 muestra que existe una correlación positiva entre el nivel de ingreso y la escolaridad del jefe de familia. Para los niveles de educación bajos (sin instrucción, preescolar, primaria incompleta y primaria incompleta) el ingreso promedio por hogar no supera los MXN\$10 000 mensuales; si se considera que, en promedio, las familias se encuentran integradas por 3.8 personas, el ingreso promedio por persona de ese segmento de escolaridad es de poco más de MXN\$2 500 mensuales.

Para los niveles educativos de secundaria incompleta hasta preparatoria completa, los ingresos mensuales por hogar oscilan entre MXN\$10 y 15000 mensuales por hogar, es decir, cerca de MXN\$3 000 mensuales por persona. Los hogares que tienen un jefe de familia con escolaridad a nivel de posgrado, los ingresos mensuales crecen de manera importante, llegando a poco más de MXN\$44000 al mes, con un ingreso promedio por integrante de MXN\$14 000 .

Gráfica 4. Nivel educativo e ingreso trimestral por hogar, 2016

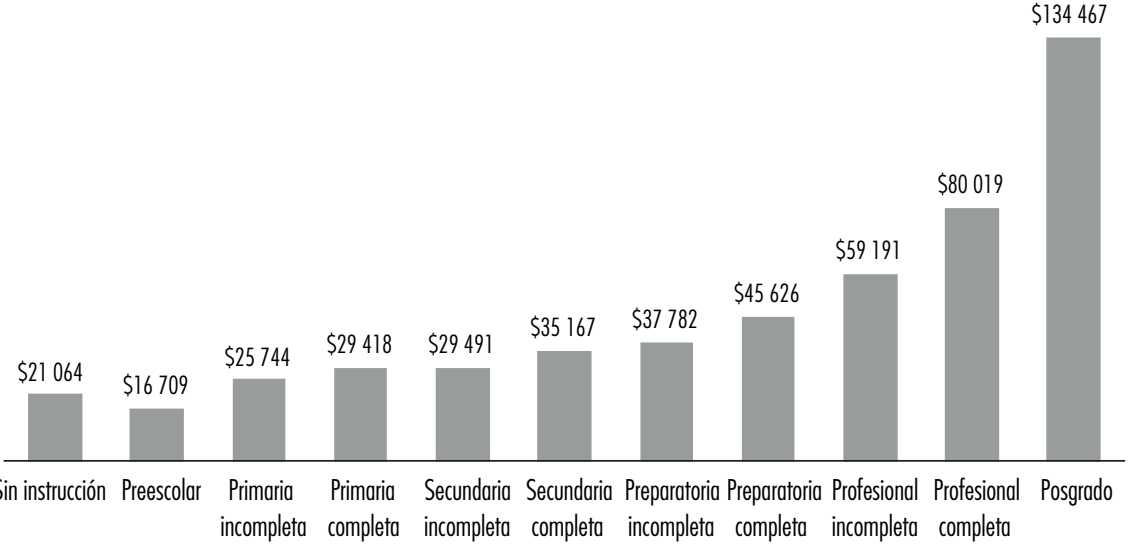

Fuente: elaboración propia con datos del INEGI, 2016. 
El cuadro 1 muestra la diferencia salarial que existe por nivel educativo, pero ahora incorporando la variable de género del jefe de familia; como se puede apreciar, la diferencia salarial entre hombres y mujeres es prácticamente inexistente para los niveles educativos bajos (hasta primaria completa), e incluso, en algunos casos los ingresos por hogar con jefe de familia mujer llegan a ser mayores que los de los hombres; sin embargo, a medida que se avanza hacia niveles de estudios superiores, la diferencia tiende a ser mayor en favor de los hombres, hasta llegar a profesional completo y posgrado, en donde la diferencia se dispara hasta 21 y $57 \%$, respectivamente. ${ }^{4}$

Cuadro 1. Diferencia salarial en hogares por género del jefe de familia

\begin{tabular}{lrrr}
\hline Nivel educativo & $\begin{array}{r}\text { Hombre } \\
(\$)\end{array}$ & $\begin{array}{r}\text { Mujer } \\
(\$)\end{array}$ & $\begin{array}{r}\text { Diferencia } \\
\text { salarial (\%) }\end{array}$ \\
\hline Sin instrucción & 21264 & 20758 & 2 \\
Preescolar & 16046 & 17637 & -9 \\
Primaria incompleta & 26081 & 24912 & 5 \\
Primaria completa & 29192 & 30062 & -3 \\
Secundaria incompleta & 30413 & 26564 & 14 \\
Secundaria completa & 35266 & 34864 & 1 \\
Preparatoria incompleta & 38252 & 35459 & 8 \\
Preparatoria completa & 45869 & 44594 & 3 \\
Profesional incompleta & 59134 & 59390 & 0 \\
Profesional completa & 82974 & 68820 & 21 \\
Posgrado & 147251 & 93822 & 57 \\
\hline
\end{tabular}

Fuente: elaboración propia con datos del INEGI, 2016.

Ahora bien, la misma información puede ser analizada considerando un nivel de agregación distinto, como el estrato socioeconómico; en esa dirección, la ENIGH contempla cuatro distintos niveles, cuya distribución de

4 Si bien, no es materia de estudio del presente trabajo, esas cifras muestran la enorme discriminación de género que existe en la obtención de puestos de trabajo calificados y de altos ingresos. 
variables seleccionadas se muestra en el cuadro 2. Como se puede apreciar, si se considera al total de hogares contemplados en la muestra, tan sólo 7\% de los hogares cae dentro del estrato socioeconómico alto. También, a medida que se tiene un estrato mayor, la capacidad de ahorro como porcentaje del ingreso, tiende a ser mayor; de hecho, para todos los estratos existe una capacidad de ahorro positiva, que va desde $4.6 \%$ del ingreso hasta $8.8 \%$ para el caso del estrato más alto.

La agrupación de información del cuadro 2, no permite apreciar de manera directa la situación de endeudamiento de los hogares. El cuadro 3, contempla solamente a los poco más de 9 mil hogares ( $46 \%$ del total de la muestra), que tienen gastos trimestrales superiores a sus ingresos, es decir, considera sólo a los hogares en situación de algún tipo de endeudamiento. ${ }^{5}$ Lo que se observa es que, en promedio, el nivel socioeconómico bajo de este subconjunto de hogares gasta en promedio 34\% más de lo que percibe en ingresos; la deuda de los hogares con nivel socioeconómico más alto, tiende a ser de 3 a $4 \%$ menor, llegando a ser de $31 \%$ para el nivel socioeconómico medio bajo, $30 \%$ para el medio alto y $31.3 \%$ para el alto (véase cuadro 3 ).

Esta situación pudiera explicarse porque, dado el bajo nivel de ingreso corriente percibido por los hogares de estrato socioeconómico bajo (alrededor de MXN\$5 500 mensuales por hogar), la vulnerabilidad financiera ante eventualidades como enfermedades u otro tipo de gastos imprevistos, tiende a ser mucho mayor, dejando al endeudamiento como una salida viable.

Lo anterior muestra que la proporción de endeudamiento en los hogares con niveles socioeconómicos menores, tiende a ser mayor, hecho que incrementa la probabilidad de incurrir en sobreendeudamiento, debido a la dificultad de estos segmentos para generar ingresos superiores a los gastos en proporciones tales que se cubra la deuda adquirida y el pago de intereses correspondientes (etapa especulativa en el esquema de Minsky para endeudamiento de empresas).

Si bien el objetivo de este trabajo es encontrar los factores que determinan la existencia de sobreendeudamiento a escala del hogar, a medida que el porcentaje total de hogares que se encuentran en esta situación tiende a ser mayor, los riesgos asociados al creciente endeudamiento adquieren dimensiones que escalan hacia el ámbito macroeconómico.

5 Cabe la posibilidad de que ese gasto por encima del ingreso provenga de algún tipo de ahorro pasado; sin embargo, se verificó que el hogar no tuviera depósitos en cuentas de ahorros, tandas, cajas de ahorro, etcétera. En caso de que un hogar contara con esa variable, se excluyó de la muestra. 
Cuadro 2. Ahorro de los hogares (ingresos - gastos) por nivel socioeconómico en México

\begin{tabular}{lrrrr}
\hline $\begin{array}{l}\text { Estrato } \\
\text { socieconómico }\end{array}$ & $\begin{array}{r}\text { Distribución de } \\
\text { hogares }\end{array}$ & $\begin{array}{r}\text { Ingreso trimestral } \\
\text { promedio por } \\
\text { hogar }(\$)\end{array}$ & $\begin{array}{r}\text { Ahorro trimestral } \\
\text { promedio por } \\
\text { hogar }(\$)\end{array}$ & $\begin{array}{r}\text { Ahorro como } \\
\text { porcentaje del } \\
\text { ingreso (\%) }\end{array}$ \\
\hline Alto & 1492 & 92592 & 8183 & 8.8 \\
Medio alto & 3776 & 50143 & 3351 & 6.7 \\
Medio bajo & 10200 & 34183 & 1879 & 5.5 \\
Bajo & 4011 & 21762 & 1012 & 4.6 \\
\hline Total general & 19479 & 39193 & 2469 & 6.30 \\
\hline
\end{tabular}

Fuente: elaboración propia con datos del INEGI, 2016.

Cuadro 3. Hogares con ahorro negativo por nivel socioeconómico

\begin{tabular}{lrrrr}
\hline $\begin{array}{l}\text { Nivel } \\
\text { socieconómico }\end{array}$ & $\begin{array}{r}\text { Distribución de } \\
\text { hogares }\end{array}$ & $\begin{array}{r}\text { Ingreso trimestral } \\
\text { promedio por } \\
\text { hogar }(\$)\end{array}$ & $\begin{array}{r}\text { Ahorro trimestral } \\
\text { promedio por } \\
\text { hogar }(\$)\end{array}$ & $\begin{array}{r}\text { Endeudamiento } \\
\text { como porcentaje } \\
\text { del ingreso (\%) }\end{array}$ \\
\hline Alto & 641 & 70615 & -22114 & -31.3 \\
Medio alto & 1619 & 40897 & -12308 & -30.1 \\
Medio bajo & 4827 & 26994 & -8333 & -30.9 \\
Bajo & 1972 & 16563 & -5696 & -34.4 \\
\hline Total general & 9059 & 30295 & -9445 & -31.2 \\
\hline
\end{tabular}

Fuente: elaboración propia con datos del INEGI, 2016.

A ello, hay que sumar que si bien ciertos tipos de sobreendeudamiento pueden estar relacionados a comportamientos y a variables específicas del hogar, a nivel general, cuando cerca del $50 \%$ de los hogares muestra patrones recurrentes de gastos superiores a sus ingresos, las causas del endeudamiento deben buscarse en el ámbito macroeconómico y en las políticas económicas que han coadyuvado a esa configuración. 


\section{Metodología}

Para evaluar cuáles son las variables que determinan el nivel de endeudamiento de los hogares en México, se utiliza la metodología de RNA. Se seleccionó esta metodología, ya que permite evaluar tanto relaciones causales lineales, como no lineales; lo que en principio permite avanzar en la comprensión del comportamiento de sistemas complejos, como es el caso de las unidades de estudio aquí analizadas. De manera adicional, los análisis de RNA permiten obtener bajo ciertas circunstancias resultados superiores a los de los modelos econométricos (Arrieta et al., 2009; Piñeiro et al., 2013).

Esta forma de evaluación consiste en una simulación del proceso de aprendizaje del cerebro humano. Cada una de las observaciones es utilizada para generar conocimiento de la manera (forma funcional, que puede ser lineal o no lineal) en la que ocurre la transmisión de las variables incluidas en el modelo hacia la variable de aprendizaje (variable dependiente).

A diferencia de lo que ocurre en los modelos econométricos, en donde se supone una forma funcional a priori, ligada al tipo de modelo a estimar, en las estimaciones mediante RNA, la forma funcional es determinada mediante el propio proceso de aprendizaje, y no depende del cumplimiento de supuestos de "buen comportamiento" vinculados al tipo de modelo seleccionado.

De acuerdo con Longoni et al. (2010), las RNA son herramientas cuyo potencial consiste en analizar datos con el objeto de descubrir y modelar las relaciones funcionales existentes entre las variables. De manera adicional, permiten explorar relaciones o modelos que no podrían ser descubiertos usando procedimientos estadísticos tradicionales.

Ello ocurre debido al proceso de aprendizaje; si mediante este proceso se determina que el impacto sobre la capa de salida tiene una forma no lineal, entonces la forma funcional se ajustará para mostrar resultados no lineales; si una relación lineal es la que mejor describe la relación entre las capas de entrada y capa de salida, la capa oculta estimara de manera lineal y no considerará, aquellas relaciones que sean redundantes o que no ejerzan impacto sobre la capa de salida.

De esta manera, un modelo de RNA está conformado por tres partes: la primera, se conoce como capa de entrada y se conforma por las variables que teóricamente inciden en la determinación de la variable a estimar. La segunda

6 Por lo general, en los modelos econométricos se asumen supuestos de normalidad, homoscedasticidad, no muticolinealidad, e incluso requerimientos de cointegración, etcétera, relativos a la forma funcional específica que se tiene cada modelo. 
parte, es conocida como capa oculta, y es ahí donde se genera el proceso de aprendizaje de las neuronas. Mientras que la tercera, es conocida como capa de salida, y está constituida por las observaciones de la variable a estimar.

La forma específica en la que se estructuran estas tres partes, se denomina arquitectura de red; si bien existen distintas arquitecturas y tipos de red, se decidió trabajar con un tipo específico por la característica que tiene de reaccionar muy rápido a alteraciones o cambios, que son medibles y conocidos, esto es, una red de tipo perceptrón multicapa, cuya forma de aprendizaje es de retropropagación.

Como ocurre con las neuronas biológicas reales, la información de las RNA es procesada cuando el estímulo tiene cierta magnitud, de lo contrario se ignora; ello se logra mediante un valor umbral $\mathrm{m}_{\mathrm{j}}$, que se activa cuando la suma ponderada supera un valor determinado y, sólo entonces, se considera la salida efectiva de la información procesada. A diferencia de lo que ocurre en los procedimientos econométricos, la información redundante queda excluida por el propio procedimiento. Ello se expresa mediante la función:

$\sum_{j} w_{i j} x_{j}-m_{i}$

Los umbrales de activación se relacionan con la intensidad de las conexiones sinápticas, que en términos de la metodología de RNA se determinan por una función de activación, ya sea de las capas ocultas, o bien, de la capa de salida.

Las capas ocultas se caracterizan por no tener conexión directa con el entorno, sino que reciben información y datos de la capa de entrada; es aquí en donde mediante el proceso de aprendizaje se modelan, representan y estiman las características obtenidas del entorno mediante la función:

Capa oculta: $a_{j}^{1}=\sum_{l} W_{j l}^{1} X_{l}+\theta_{j}^{1} ; h_{j}=f^{1}\left(a_{j}^{1}\right)$

Por último, se encuentra la capa de salida, compuesta por los conjuntos de neuronas que proporcionan la respuesta de la red, mediante la función:

Capa de salida: $a_{j}^{2}=\sum_{l} W_{j l}^{2} X_{l}+\theta_{j}^{2} ; h_{j}=h^{2}\left(a_{j}^{2}\right)$ 


\section{Entrenamiento de las neuronas}

El proceso de entrenamiento de las neuronas o proceso de aprendizaje permite obtener las formas funcionales de los datos obtenidos procedentes de la capa de entrada y se realiza para un subconjunto de datos $D=\left\{X^{(n)}, t^{(n)}\right\}$.

De manera gradual, se ajusta la función de entrada $W$, mediante la minimización del error de la función, a través del método conocido como descenso del gradiente, representado mediante la función:

$$
\begin{aligned}
J\left(W_{0}\right) & \geq J(W) \\
J\left(W_{n+1}\right) & \geq J\left(W_{n}\right) \\
W_{n+1} & =W_{n}-\mu \frac{1}{2} \nabla J_{w}\left|W_{n}=W_{n}-\frac{\mu}{2} \frac{\partial J w}{\partial w}\right| w_{n} \\
E_{D}(w) & =\frac{1}{2} \sum n \sum i\left(\left(t_{i}^{(n)}-y_{i}\left(x^{(n)} ; w\right)\right)^{2}\right.
\end{aligned}
$$

La minimización se basa en evaluar continuamente el gradiente de $\mathrm{E}_{\mathrm{D}}$ mediante la regla de la cadena para encontrar las derivadas.

El resultado del proceso de minimización mediante el descenso del gradiente es una aproximación de los valores de la capa de salida, de una muestra reservada del total de datos, distinta a las observaciones utilizadas en proceso de entrenamiento de la neurona.

De manera reciente se han hecho esfuerzos por tratar de abonar a la interpretación de los resultados estimados de las redes neuronales y generar, al menos, alguna información relativa al orden jerárquico en el que las variables actúan sobre el fenómeno de estudio. Es en esa dirección que se utilizó un tipo de análisis que se basa en la magnitud de los pesos y, de manera específica, a un conjunto de exámenes basados en la comparación de la matriz de los pesos sinápticos de la capa de entrada hacia la capa oculta, con la intención de obtener información relativa al impacto o influencia que tienen las variables de entrada sobre las de salida de la red. De esta forma, para medir los pesos sinápticos de las variables y su impacto sobre la variable de salida, se tiene la siguiente función (Montaño et al., 2002):

$$
Q_{i k}=\frac{\sum_{j=1}^{L}\left(\frac{W_{i j} V_{j k}}{\sum_{r=1}^{N} W_{r j}}\right)}{\sum_{i=1}^{N}\left(\sum_{i=1}^{L}\left(\frac{W_{i j} V_{j k}}{\sum_{r=1}^{N} W_{r j}}\right)\right)}
$$


De esta forma, se estima el análisis de la importancia de la variable, que permite conocer la jerarquía (únicamente en términos de orden, pero no de magnitud de su impacto) de las variables de la capa de entrada sobre la de salida.

\section{RESULTADOS}

Con la intención de contrastar la hipótesis, se aplicó la metodología descrita en la sección anterior, a los microdatos provenientes de la ENIGH. De las poco más de 19 mil observaciones disponibles en la encuesta, se consideraron para estimar el modelo de RNA 9059 hogares, que corresponden a las unidades de estudio con gastos mayores a los ingresos. Como se puede observar en el cuadro 4 , el $71.4 \%$ de los datos fueron utilizados en la etapa de entrenamiento (es decir, para analizar la correspondencia entre las variables de la capa de entrada y la de salida), el $19.3 \%$ para la realización de pruebas y el $10.3 \%$ restante corresponden a la muestra de reserva, utilizada para validar los resultados.

En el modelo se emplea como variable dependiente el nivel de endeudamiento, mientras que los factores utilizados son: la edad del jefe familiar, el sexo, el nivel educativo, el estrato socioeconómico, el número de dependientes económicos, el pago a tarjetas de crédito y el pago de otras deudas.

De acuerdo con la teoría, la variable edad se encuentra relacionada con las decisiones de endeudamiento de manera negativa. A mayor edad, los individuos tienden a acumular mayores conocimientos y habilidades relacionados con la experiencia, a la vez que se comportan de manera más estable y menos arriesgada, lo que contribuye a incrementar el nivel de responsabilidad, influyendo en su aversión al sobreendeudamiento.

Cuadro 4. Resumen de procesamiento de casos

\begin{tabular}{llrr}
\hline & & $N$ & Porcentaje \\
\hline Ejemplo & Entrenamiento & 6298 & 71.4 \\
& Pruebas & 1707 & 19.3 \\
& Reserva & 819 & 9.3 \\
Válido & & 8824 & 100.0 \\
Excluido & & 235 & \\
Total & & 9059 & \\
\hline
\end{tabular}

Fuente: elaboración propia con resultados de la estimación de RNA. 
Por otro lado, conforme la edad productiva de las personas tiende a disminuir, se tiende a ahorrar un porcentaje mayor en relación con su ingreso, para cubrir necesidades de edades más avanzadas; mientras que, a medida que se incrementa el ingreso, las personas al haber cubierto las necesidades básicas pueden generar ahorros. Algo similar ocurre al incrementar el nivel educativo de las familias, factor que brinda la posibilidad de acceder a trabajos con salarios mayores. Debido a lo anterior, se esperaría que tanto la edad, como el nivel educativo, impacten de manera negativa en las decisiones de endeudamiento.

En cuanto al estrato socioeconómico, la teoría señala dos direcciones: por un lado, el nivel socioeconómico está ligado a la oportunidad de tener un mayor nivel de estudios, por lo que, en teoría, estratos socioeconómicos más altos tienen mayor acceso a educación financiera y, por ello, hay menos probabilidad de que caigan en endeudamiento. Por otro lado, es más probable que una persona de un nivel socioeconómico alto obtenga acceso a crédito con cierta facilidad, ya que se cuenta con mayores ingresos y garantías.

Sin embargo, también se reconoce que el estrato socioeconómico está ligado con un mayor nivel educativo y con un mayor conocimiento sobre el funcionamiento operacional y legal del sistema financiero; por lo que el conocimiento sobre la ausencia de sanciones ante incumplimiento de pago hace que, en ocasiones, familias de mayores estratos socioeconómicos decidan no pagar sus deudas, una vez que enfrenta problemas para cumplir con las mismas. De modo contrario, la gente de estratos socioeconómicos bajos cuenta con escaso acceso al financiamiento y desconoce el funcionamiento de este, por lo que, en su afán de mantener abierta la puerta al crédito y evitar problemas, mantiene un mejor patrón de cumplimiento crediticio.

En cuanto a la variable dependientes económicos se espera que, a mayor número de dependientes económicos, existan más necesidades que cubrir y será más probable caer en endeudamiento ante cualquier eventualidad. En este mismo sentido, la variable pago a tarjetas y pago de deudas tienen un impacto positivo en el nivel de endeudamiento y representan una carga financiera que pone a las familias en situación de fragilidad ante un desequilibrio o eventualidad negativa (enfermedad, accidentes, fallecimiento, entre otros). Lo anterior es particularmente patente para el caso de la economía mexicana, en donde la diferencia entre las tasas de interés activas y pasivas es grande.

La red utilizada es de tipo perceptrón multicapa de una capa oculta; la capa de entrada consta de 857 unidades (sin incluir la unidad de sesgo). El número de unidades de la capa oculta es de 5 , con una función de activación de tangente hiperbólica. 
La capa de salida tiene una unidad, y fue estimada con una función de activación identidad y una función de error basada en suma de cuadrados. Los resultados son sintetizados en el cuadro 5 .

El cuadro 6 muestra un error de estimación del modelo relativamente bajo, tanto para las pruebas realizadas, como para la muestra de reserva que es utilizada para validar las estimaciones, lo que indica que la estimación es robusta en términos de las variables seleccionadas. ${ }^{7}$

El análisis de la importancia sobre las variables independientes, señala cuánto cambia el valor pronosticado por el modelo de la red para diferentes valores de la variable dependiente. La importancia normalizada es el resultado de los valores de importancia divididos por los valores de importancia mayores expresados como porcentajes (véase gráfica 5).

Cuadro 5. Información de red

\begin{tabular}{|c|c|c|c|}
\hline \multirow[t]{8}{*}{ Capa de entrada } & \multirow[t]{7}{*}{ Factores } & 1 & Sexo \\
\hline & & 2 & Estrato socioeconómico \\
\hline & & 3 & Nivel educativo \\
\hline & & 4 & Edad jefe \\
\hline & & 5 & Dependientes económicos \\
\hline & & 6 & Pago_Tarjetas \\
\hline & & 7 & Pago de deudas \\
\hline & Número de unidades ${ }^{0}$ & & 857 \\
\hline \multirow[t]{3}{*}{ Capas ocultas } & Número de capas ocultas & & 1 \\
\hline & Número de unidades en la capa oculta $1^{0}$ & & 5 \\
\hline & Función de activación & & Tangente hiperbólica \\
\hline \multirow[t]{5}{*}{ Capa de salida } & Variables dependientes & 1 & Endeudamiento \\
\hline & Número de unidades & & 1 \\
\hline & Método de cambio de escala para las dependientes de escala & & Estandarizados \\
\hline & Función de activación & & Identidad \\
\hline & Función de error & & Suma de cuadrados \\
\hline
\end{tabular}

Nota: ${ }^{a}$ se excluye la unidad de sesgo.

Fuente: elaboración propia con resultados de la estimación de RNA.

7 Para el entrenamiento de la neurona, en forma del gradiente conjugado escalado, se partió de un valor inicial de lambda de 0.0000005 , una sigma inicial de 0.00005 y un desplazamiento del intervalo de \pm 0.5 . 
Héctor Eduardo Díaz, Miriam Sosa y Alejandra Cabello

Cuadro 6. Resumen del modelo

\begin{tabular}{llr}
\hline Entrenamiento & Error de suma de cuadrados & 2967.052 \\
& Error relativo & .942 \\
& Regla de parada utilizada & 1 paso(s) consecutivo(s) sin disminución del error ${ }^{0}$ \\
& Tiempo de entretamiento & $0: 00: 04.99$ \\
\hline Pruebas & Error de suma de cuadrados & 389.062 \\
& Error relativo & .937 \\
\hline Reserva & Error relativo & .928 \\
\hline
\end{tabular}

Notas: variable dependiente: endeudamiento; ${ }^{a}$ los cálculos de error se basan en la muestra de comprobación. Fuente: elaboración propia con resultados de la estimación de RNA.

Grática 5. Análisis de importancia normalizada

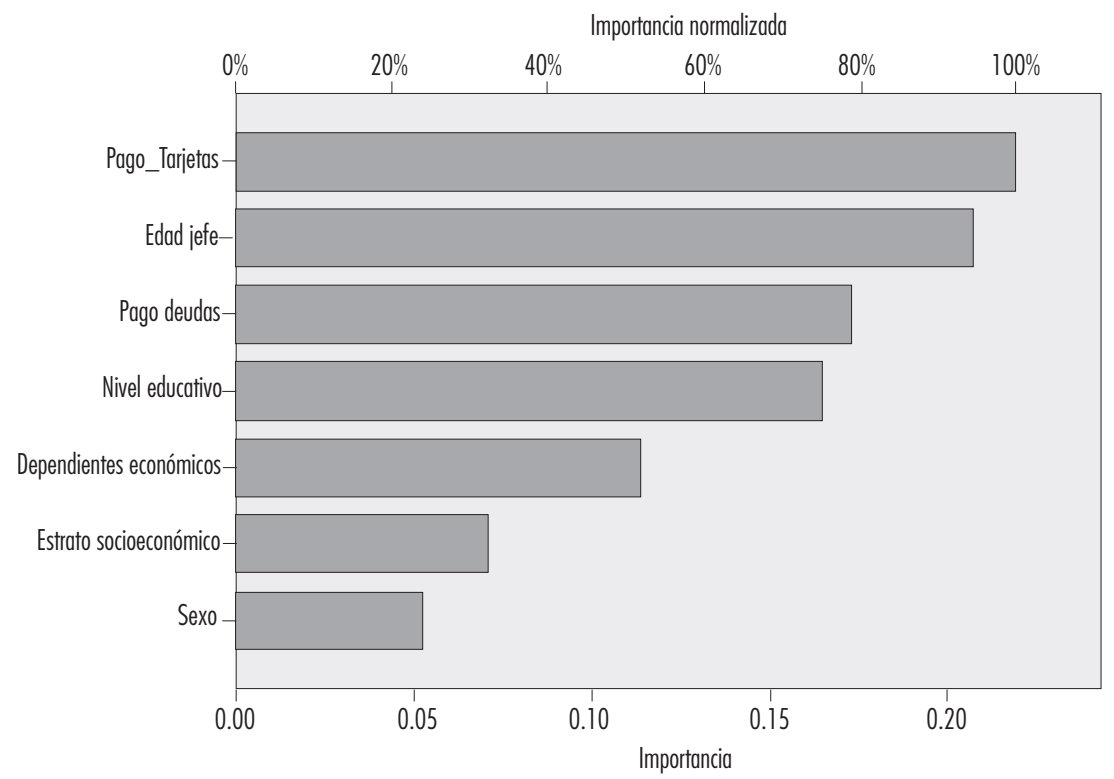

Fuente: elaboración propia con resultados de la estimación de RNA. 
La evidencia de la presente investigación señala que, para el modelo estimado, la variable más importante para determinar el nivel de endeudamiento es la tenencia de una tarjeta de crédito.

Si bien puede pensarse que las variables de sobreendeudamiento y la tenencia de tarjetas se encuentran correlacionadas entre sí, el modelo de red neuronal permite entender que no en todos los casos la existencia de una tarjeta se relaciona con el sobreendeudamiento, sino que los patrones específicos en el uso del crédito son los que determinan cuándo ocurre y cuándo no.

Este resultado es, quizá, uno de los más relevantes del presente estudio, ya que indica que cuando las personas utilizan una tarjeta de crédito se impone una alta carga financiera al tarjetahabiente, debido a las altas tasas de interés cobradas por los bancos comerciales y las tiendas departamentales, que representan una fuga de recursos y, en última instancia, una transferencia del ingreso familiar al sector bancario.

El resultado anterior, si bien, contrasta con la mayoría de los estudios relacionados, también es intuitivo, sobre todo si se considera que el costo anual total (la suma de la tasa de interés y conjunto de comisiones bancarias que se pagan por una tarjeta de crédito), representa una fuga de dinero de los hogares que oscila, dependiendo el tipo de tarjeta (entre 56 y $177 \%$ adicional por año del monto del crédito), de acuerdo con datos del Banco de México (2017). ${ }^{8}$ El hecho de que el costo del crédito al consumo y el diferencial entre tasas activas y pasivas en México sea tan alto, contribuye a explicar por qué la existencia de un crédito vigente, es un factor que contribuye a entender sobreendeudamiento de las familias.

\section{CONCLUSIONES}

El objetivo de la presente investigación es analizar los principales determinantes de endeudamiento de los hogares mexicanos. El análisis emplea la metodología de RNA a partir de un modelo que propone como variable dependiente el sobreendeudamiento en hogares y como variables independientes la edad del jefe de familia, el sexo del entrevistado, el nivel educativo, el estrato socioeconómico, el número de dependientes económicos, el monto del pago a tarjetas de crédito y el pago de otras deudas.

8 Para el caso de las tarjetas de crédito más utilizadas (tarjetas clásicas), con datos consultados el 23 de diciembre de 2017 en el Banco de México (2017), el costo del crédito (CAT) oscila entre 56.7 y $177.7 \%$. Para el caso del crédito ofrecido directamente por tiendas departamentales, este valor va de entre 44.9 hasta $90.2 \%$ (CONDUSEF). 
La importancia del endeudamiento puede analizarse desde dos distintas perspectivas. Microeconómicamente representa una oportunidad para los hogares de acceder a recursos que podrían potenciar su bienestar, cuando el crédito es empleado para adquirir bienes de capital, o que permiten incrementar las capacidades de los integrantes del hogar; sin embargo, también es una carga financiera que impone a los hogares la obligación del pago de intereses, disminuyendo el nivel de ingreso a largo plazo y su capacidad de reacción ante eventualidades (enfermedad, accidentes, muerte del jefe de familia, entre otros), exponiendo a los hogares a la pérdida patrimonial. Desde un enfoque agregado, el peso financiero que imprime el endeudamiento a una economía limita la capacidad y las acciones ante desequilibrios externos, reduciendo las opciones en pro de la reactivación ante las crisis.

En términos de la economía mexicana, en los últimos 20 años el consumo privado creció más que el producto, a pesar de la caída en la participación de los salarios en el producto y de la disminución del poder adquisitivo de los mismos. Ello, ha generado una tendencia creciente al sobreendeudamiento de una mayor proporción de hogares. Mientras que en el contexto internacional contemporáneo, en el que impera un tipo de regulación financiera que favorece a la banca internacional y, de manera específica, en el contexto mexicano con el dominio bancario de origen extranjero, la banca ha servido como un canal de transferencia de recursos de la población en general hacia capitales cuyos orígenes se encuentran fuera del territorio nacional.

En este sentido, vale la pena reflexionar a partir de los resultados de la presente investigación, que señalan que el principal determinante del endeudamiento en la población es la tenencia de una tarjeta de crédito, la cual se utiliza para cubrir una parte del gasto corriente de los hogares (compra de calzado, vestido, comida, medicinas, etcétera). Así, el endeudamiento no responde al deseo a mejorar el bienestar de la población en el largo plazo, como señala la teoría, sino a suplir la pérdida del ingreso real, insertando un componente de riesgo y vulnerabilidad financiera, consecuencia, entre otras cosas, del establecimiento de políticas de metas de inflación, que utilizan como variable ancla los salarios nominales.

Existen importantes implicaciones de los hallazgos de esta investigación en términos de política pública y regulación bancaria. En cuestión de política pública es necesario detener y compensar la caída del salario real, disminuyendo la desigualdad; la regulación bancaria es una forma de política complementaria para atender la problemática y puede, en circunstancias actuales, reducir las altas tasas de interés en el crédito al consumo. 
En el mejor de los casos, desde una perspectiva de teoría ortodoxa, es necesario que las instituciones bancarias elaboren un perfil de crédito de cada cliente, con base en una investigación minuciosa, disminuyendo así el problema de información asimétrica, principal justificante de las altas tasas de interés asociadas a crédito al consumo. Desde una perspectiva de teoría económica heterodoxa, es necesario establecer regulaciones en el sector financiero que permitan disminuir la enorme transferencia de recursos de las familias al sector financiero internacional mediante los bancos establecidos en territorio nacional.

Una regulación que permita reducir las tasas de interés cobradas por los bancos comerciales es una condición necesaria, pero no suficiente para reducir el sobreendeudamiento de los hogares. Esa medida, debiera ser complementada con una política que permita incrementar el salario real de la población; en la medida en la que los ingresos son suficientes, la tendencia a sobre endeudarse es menor.

Contrario a la idea de que una mayor inclusión financiera mejorará el bienestar de las familias y que ello reduce el riesgo de inestabilidad financiera en las economías debido a que el acceso al crédito formal es más favorable que el informal, no hay información concluyente que asegure que el otorgamiento de crédito en mercados formales con las tasas de interés reportadas en este estudio, ocurra en condiciones más favorables que en aquellos informales. Por el contrario, pareciera que con las actuales reglas de funcionamiento del sistema financiero mexicano, que permiten la existencia de enormes diferenciales en las tasas activas y pasivas de interés, los empréstitos bancarios constituyen un factor detonante del sobreendeudamiento de los hogares.

En la misma dirección, líneas futuras de investigación podrían explorar el impacto de la inclusión financiera en términos de crecimiento económico y las condiciones de crédito en los mercados formales e informales.

\section{BIBLIOGRAFÍA}

Angulo, L. (2014), "Prácticas financieras riesgosas para afrontar la crisis económica en los hogares: entre malabarismos con el dinero y sobreendeudamiento", Desacatos, núm. 44, México, enero-abril.

Arrieta, J. E., Torres, J. C. y Velásquez, H. (2009), "Predicciones de modelos econométricos y redes neuronales: el caso de la acción de suraminv", Semestre Económico, vol. 12, núm. 25, Colombia, Univesidad de Medellín, julio-diciembre. 
Banco de México (2017), "Información Comparativa de Costos de Tarjetas de Crédito". Recuperado de <http://www.banxico.org.mx/tarjetascat/>

Banco Mundial (2013), "Reporte de desarrollo Financiero Global: Repensando el papel del estado en las finanzas", Washington, DC, Banco Mundial. Recuperado de <https://openknowledge.worldbank.org/handle/10986/11848>

Campero, A. y Kaiser, K. (2013), "Access to credit: awareness and use of formal and informal credit institutions", Working Paper, Banco de México.

Claessens, S. (2005), "Access to financial services: a review of the issues and public policy objectives", World Bank Policy Research, Working Paper S3589, Washington, D.C., World Bank.

Clarke, G., Xu, L. y Zou, H. (2003), "Finance and income inequality: test of alternative theories", World Bank Policy Research, Working Paper 2984, Washington, D.C, World Bank.

Comisión Nacional Bancaria y de Valores (CNBv) (2018), "Portafolio de Información de Tarjeras de Crédito", CNBV. Disponible en $<$ http://portafoliodeinformacion.cnbv.gob.mx/bm1/Paginas/tarjetascredito.aspx>

Consejo Nacional de Inclusión Financiera (2017), "8vo Reporte Nacional de Inclusión Financiera, Comisión Nacional Bancaria y de Valores", $C N B V$, México. Recuperado de <http://www.cnbv.gob.mx/Inclusi\%C3\%B3n/ Documents/Reportes\%20de\%20IF/Reporte\%20de\%20Inclusion $\% 20$ Financiera\%208.pdf>

Contreras, A., García, A., Juárez, I. K. y García, E. (2017), “Un estudio empírico sobre el hábito de consumo mediante el uso de tarjeta de crédito en jóvenes universitarios", European Journal of Education Studies, vol. 3, núm. 9, DOI <http://doi.org/10.5281/zenodo.852518>

Dabla-Norris, E. y Srivisal, N. (2013), "Revisiting the link between finance and macroeconomic volatility", Working Paper, núm. 13/29, Washington D.C., International Monetary Fund.

Dehejia, R. y Lleras, A. (2007), "Financial development and pathways of growth: state branching and deposit insurance laws in the United States, from 1900 to 1940", Journal of Law and Economics, vol. 50, University of Chicago Press.

Del Río, A. (2002), "El endeudamiento de los hogares españoles", Boletín Económico, núm. 0228, España, Banco de España.

Demirg, Á. y Levine, R. (2008), "Finance and economic opportunity", World Bank Policy Research, Working Paper 4468, Washington, D.C. 
Fatoki, O. (2015), "The causes and consequences of household over-indebtedness in South Africa", Journal of Social Sciences, vol. 43, núm. 2, DOI <https://doi.org/10.1080/09718923.2015.11893427>.

Honohan, P. (2004), "Financial sector policy and the poor: selected findings and issues", World Bank Policy Research, Working Paper 43, Washington, D.C., World Bank.

INEGI (2016), Encuesta Nacional de Ingresos y Gastos de los Hogares (ENIGH), México, INEgi.

Karlan, D., Ratan, A. y Zinman, J. (2013), "Savings by and for the poor: a research review and agenda", World Bank Policy Research, Working Paper 346, Washington, D.C., Center for Global Development.

Kose, M.A., Prasad, E.S. y Terrones, M.E. (2003), "Financial integration and macroeconomic volatility", Staff Papers, vol. 50, International Monetary Fund.

Levine, R. (2005), "Finance and growth: theory and evidence. Handbook of economic growth", en Ph. Aghion y S. Durlauf (eds.), Handbook of Economic Growth, edition 1, vol.1, chapter 12, Elsevier.

Longoni, M. G., Porcel, E., López, M. V. y Dapozo, G. N. (2010), "Modelos de redes neuronales perceptrón multicapa y de base radial para la predicción del rendimiento académico de alumnos universitarios", XVI Congreso Argentino de Ciencias de la Computación, Argentina.

Martínez-Carrascal, C. y Río, A. D. (2004), "Las implicaciones del endeudamiento de los hogares sobre el consumo privado", Boletín Económico, Banco de España (12).

Minsky, H. (1992), "The financial instability hypothesis. The Jerome Levy Economics Institute", Working Paper, núm. 74. Disponible en ssRn: $<\mathrm{http}: / / \mathrm{dx}$. doi.org/10.2139/ssrn.161024>

(2008), Stabilizing an unstable economy, vol. 1, Nueva York, McGraw-Hill.

Montaño, J. (2002), Redes neuronales artificiales aplicadas al análisis de datos, (Tesis Doctoral), España, Universitat de les Illes Balears.

Morales, F. J., Muñoz, G, y Uribe, E. A. (2013), "Sistema financiero y actividad económica en México: negocio y divergencia del sector bancario", Análisis Económico, vol. 28, núm. 67, México, UAM-Azcapotzalco.

Piñeiro, C., De Llano, P. y Rodríguez, M. (2013), “¿Proporciona la auditoría evidencias para detectar y evaluar tensiones financieras latentes? Un diagnóstico comparativo mediante técnicas econométricas e inteligencia artificial”, Revista Europea de Dirección y Economía de la Empresa, vol. 22, núm. 3, DOI <https://doi.org/10.1016/j.redee.2012.10.001> 
Pradilla, D. (2015), Determinantes de las condiciones de endeudamiento de los hogares colombianos (Tesis Doctoral), Chile, Universidad de los Andes.

Rajan, R. G. y Zingales, L. (1995), "What do we know about capital structure? Some evidence from international data", The journal of Finance, vol. 50, núm. 5, DOI <https://doi.org/10.2307/2329322>

Romero, J. X. (2018), Los factores financieros y sociodemográficos que influyen en el sobre-endeudamiento de los hogares ecuatorianos para el año 2014 (Tesis de Maestría), Ecuador, Universidad de Cuenca.

Ruiz-Tagle, J., García, L. y Miranda, A. (2013), "Proceso de endeudamiento y sobre endeudamiento de los hogares en chile", Documento de trabajo, 703, Banco Central de Chile.

Salgado, H. y Chovar, A. (2010), “¿Cuánto influyen las tarjetas de crédito y la deuda hipotecaria en el sobre endeudamiento de los hogares en Chile?”, Departamento de Economía, núm. 12-2010, Chile, Universidad de Concepción.

Samuelson, P. A. y Nordhaus, W. D. (1992), Economics, Nueva York, McGraw-Hill.

Schumpeter, J. (1976), Teoría del desenvolvimiento económico: una investigación sobre ganancias, capital, crédito, interés y ciclo económico, México, Fondo de Cultura Económica.

Solano, M. C., Vega, L. V. y Cárdenas, L. F. (2015), "Determinantes del uso de tarjetas de crédito en México. Reflexiones sobre el papel de la cultura financiera", Revista RAITES, año 1, núm. 1, México, Red de Investigación en Administración de la Innovación Tecnológica, Económica y Sustentable.

Straub, S. (2003), "Informal Sector: 'The credit market channel'", Working Paper, Escocia, University of Edinburgh.

Vázquez, A. (2015), "Determinantes para participar en el mercado formal de productos financieros: el caso del ahorro y del crédito en México", Estudios Económicos $C N B V$, vol. 3, México, CNBv. 